\title{
What Medical Education can do to Ensure Robust Language Development in Deaf Children
}

\author{
Tom Humphries • Poorna Kushalnagar • \\ Gaurav Mathur • Donna Jo Napoli • Carol Padden • \\ Robert Pollard • Christian Rathmann • Scott Smith
}

Published online: 9 October 2014

(C) The Author(s) 2014. This article is published with open access at Springerlink.com

\begin{abstract}
The typical medical education curriculum does not address language development for deaf and hard-of-hearing (DHH) children. However, this issue is medical because of the frequency with which DHH children as a population face health complications due to linguistic deprivation. The critical period for language development is early; if a child does not acquire an intact language before age five, the child is unlikely to ever have native-like use of any language. Such linguistic
\end{abstract}

\section{T. Humphries}

Education Studies and Department of Communication, University of California at San Diego, La Jolla, CA, USA

P. Kushalnagar

Chester L. Carston Center for Imaging Science, Rochester Institute of Technology, Rochester, NY, USA

\section{G. Mathur}

Department of Linguistics, Gallaudet University, Washington, DC, USA

\section{J. Napoli ( $\bowtie)$}

Department of Linguistics, Swarthmore College, 500 College Ave., Swarthmore, PA 19081, USA

e-mail: dnapoli1@swarthmore.edu

C. Padden

Department of Communication, University of California at San

Diego, La Jolla, CA, USA

\section{R. Pollard}

University of Rochester Medical Center School of Medicine and Dentistry, and Director of the Deaf Wellness Center, Rochester, NY, USA

\section{Rathmann}

Institute for German Sign Language and Communication of the Deaf, Universität Hamburg, Hamburg, Germany

\section{S. Smith}

Department of Public Health Sciences, University of Rochester Medical Center, Rochester, NY, USA deprivation carries risks of cognitive delay and psycho-social health difficulties. Spoken language is inaccessible for many DHH children despite assistive-technology developments. But sign languages, because they are visual, are accessible to most DHH children. To ensure language development, DHH children should have exposure to a sign language in their early years, starting at birth. If they also receive successful training in processing and producing a spoken language, they will have the many benefits of bimodal bilingualism. Undergraduate medical education curricula should include information about early language acquisition so that physicians can advise families of deaf newborns and newly deafened young children how to protect their cognitive health. Graduate medical education in primary care, pediatrics, and otolaryngology should include extensive information about amplification/cochlear implants, language modality, and the latest research/practices to promote the development and education of DHH children. Training in how to establish connections with local authorities and services that can support parents and child should be included as well. Further, students need to learn how to work with sign language interpreters in caring for $\mathrm{DHH}$ patients. We offer suggestions as to how medical curricula can be appropriately enriched and point to existing programs and initiatives that can serve as resources.

Keywords Brain plasticity $\cdot$ Cochlear implants $\cdot$ Cognitive development $\cdot$ Deaf and hard-of-hearing children $\cdot$ First language acquisition

\section{Introduction}

Presently, there is a dearth of information about matters related to deaf and hard-of-hearing children across the spectrum of medical education, from medical school curricula, to residencies, to continuing medical education programs. In this paper, 
we focus on those matters crucial to the cognitive health of deaf or hard-of-hearing (DHH) children, the most critical of which is language development. Children must be exposed to an accessible language on a regular and frequent basis before the age of five in order to develop full language competence. The window of opportunity is small. Linguistic deprivation leads to a range of cognitive deficits and psycho-social problems, including academic failure.

When a DHH child is born, typically the focus of medical professionals is on restoring listening ability, particularly the ability to hear speech. However, spoken language can frequently be auditorily inaccessible to the child, even with a hearing aid or cochlear implant $(\mathrm{CI})$, with the result that language acquisition is affected and possibly delayed. Sign languages are visually accessible to DHH children and can be acquired intact from birth. For DHH children who are blind, a sign language can be acquired through tactile input (perceiving a sign language by placing the hands on the signers' hands to follow the movement and shape of signs). With the benefit of development in a sign language, a first language, $\mathrm{DHH}$ children can transfer this language and cognitive ability to developing a second, spoken language as well, with the added linguistic, cognitive, and educational benefits of bimodal bilingualism.

Information on brain plasticity as it relates to first language acquisition, on the effects of linguistic deprivation, on the variability of spoken language success with a $\mathrm{CI}$, and on the benefits of bilingualism for everyone, including DHH children, are essential in the education of medical professionals preparing to meet standards of care and to do no harm. These next sections discuss some of the most recent research and findings that we suggest need to be covered in medical education.

\section{Brain Plasticity and Critical Periods}

The brain is a dynamic organ and continues to change through the lifespan of an individual. Natural development in the early years, variation in exposure and environment, and injury can lead to differences in shaping neural pathways and synapses [1-8]. Still, there are neurological and cognitive functions for which the brain appears to lose plasticity at some point during the early years. The time between birth and the point in time when mastery of a neurocognitive function becomes much more difficult is termed the "critical period" for that particular neurocognitive function [9].

There is considerable evidence for critical periods for a number of essential neurocognitive functions, including vision [10] and hearing [11-15]. As a result, the age at which congenitally deaf children are recommended for CIs has grown progressively younger. Most implantations are now done before a child becomes 2 years old, and many are done before age one $[16,17]$.
The critical period for language development, spoken or sign, is unique, however, and independent of the critical periods for auditory and visual capabilities. Language development is a natural development for an infant with normal hearing and vision. Language development tends to be successful as well for blind infants with normal hearing if they are provided with adequate auditory stimuli from birth [18]. Likewise, language development is a natural development for DHH infants with normal vision if these infants are provided with adequate visual language input [19]. However, if a child is not provided with adequate language input (whether auditory or visual), on a frequent and regular basis up to age five, the child is unlikely to attain native or native-like fluency in any language [20-33].

The Critical Period for First Language Acquisition and DHH Children

DHH people who do not receive accessible language input (i.e., no sign language and inadequate spoken language input) until after age five show impaired language facility [34-40]. Further, DHH children raised orally (with hearing and speech only) and first exposed to a sign language at varying later ages show varying degrees of language development as they age, with early learners doing far better than late learners [41-52].

Many children are given hearing aids and/or CIs at a young age. Hearing aids do not present the surgical risks of CIs (discussed below) and may offer comparable or better advantages for speech development depending on the circumstances of individual children [53]. However, while some DHH children gain access to language via speech through hearing aids and/or CIs, some do not [54-57]. Studies report highly variable success [58-62]. Without a meta-study to compare rates and reasons for CI effectiveness across studies, it is impossible to glean what findings these studies have in common; they use different methodologies, test for different auditory functions, and study heterogeneous groups [63]. Studies of implanted children's language skills in daily communication (as opposed to selected speech skills within a laboratory setting) reveal that a large percentage demonstrate weakness in language competence [64-69], even when implanted very young [70]. Even among children who are deemed successful with the $\mathrm{CI}$, there is evidence of cognitive difficulties [71-74]. Some CI children receive no discernible auditory benefit, much less language benefit [75], and some (in one study, $47 \%$ ) stop using their CI [76]. Even if the failure rate should turn out to be much lower, such as $5 \%$, the risk that $5 \%$ of young developing deaf children who are implanted will not get accessible language during the critical period is not ethically acceptable. Medical education curricula need to ensure that the effects of listening technologies are not overstated as well as help student to understand how they can be beneficial. 
Optimism that technological advances will lead to dramatic improvements in machines that interface with how the brain functions may be misplaced [77, 78], particularly for CI success, since the issue is not one of better technology, but, as Robert Shannon and colleagues write, of better "understanding how implant speech processors may be more effectively programmed and customized for individual patients, so that the capabilities that are already available may be fully utilized" [79]. As Tom Humphries and colleagues say, "The brain is complex, and hearing is complex. There is no reason to expect a quick and huge rise in success of CIs from an advance in technology. In any case, we must deal with the technology we presently have" [56].

Further, all surgeries carry risks, and complications can arise from CI surgeries [80-83], including risk of vertigo after surgery $[84,85]$, and of apparatus damage or technical failure that requires repeated surgery $[86,87]$. As the popularity of binaural implantation goes up, risks go up [88], while the claimed benefits do not always materialize for all implanted children [89].

As a final point, CI surgeries do not always have promising results. Surgeries that disable the cochlea destroy residual hearing [68], and, if unsuccessful, have a contrary result to their very intention. Some children risk losing ground on speech skills [90]. New developments in brain stem implantation potentially raise similar or greater concerns. While the inclination is to put much trust and hope in newer technologies such as the CI, medical professionals who understand the above limitations are better informed and can give more realistic medical treatment and advice to parents and patients.

It is highly likely that medical education curricula already include or cover such treatments, therapies, and procedures as those associated with hearing aids and CIs. In contrast, sign languages and the acquisition of sign language are rarely, if ever, included as essential topics for medical students to understand. In particular, the following points are important for medical students to grasp. Language that is signed is accessible to DHH children. DHH children who acquire a sign language during the critical period exhibit full linguistic competence in their native sign language [40,91], as well as perform similarly to hearing children on tests involving competence in a second language [51, 52]. Additionally, there are several small studies that address spoken language development in CI users whose first language is a sign language which show that the introduction of sign language development does not impede the development of spoken language, and may actually promote its development $[92,93]$.

Moreover, early acquisition of a sign language has longterm health implications. DHH people who do not use sign language have a higher incidence of mental health problems than signers [94]. Indeed, in providing DHH children with a path of least resistance to language development through visual input, a sign language has multiple psycho-social as well as cognitive benefits $[53,55]$. While not only the medical profession but society as a whole often think of deafness as a pathology or deficit, signing DHH children and adults show neither a pathology nor deficit and often demonstrate great language and communication flexibility [95, 96]. Healthy functioning of a DHH person has little to do with the traditional medical focus on amplification/CIs and oral education, and very much to do with a firm footing in a first language.

Potential Benefits for DHH Children of Improving Medical Curricula

Appropriate information about language acquisition, particularly sign language acquisition, added to the overall medical curricula at various points in a student's education can lead to a number of benefits for DHH children, with the ultimate result of protecting their cognitive health. We suggest ways this information can be inserted into and tailored to different levels and specialty areas of medical education. Existing innovative programs and initiatives, also discussed here, can serve as resources as medical institutions consider ways to implement curricula that address language and cognitive development for DHH children.

\section{Undergraduate Medical Education}

Medical professionals deal not just with medical issues, but with people; accordingly, cultural competency has become an element in undergraduate medical education given our diverse society $[97,98]$. The kind of cultural humility needed in medicine calls for a commitment to lifelong self-evaluation and self-critique [99] and could well begin in the college years before medical school [100], even. In undergraduate preclinical medical courses, exposure to a sign language and to deaf culture through lectures and encounters with high-functioning deaf signers would develop that competency in relation to a large community of American Sign Language users in the USA. Electives that encourage learning a sign language would also help, although it is essential that medical professionals do not adopt the unrealistic goal of fluency from just one short course and get the notion that would be sufficient training to avoid the need for professional interpreters during DHH patient care [101, 102]. Lectures on brain plasticity and first language development would alert students about the importance of early exposure to an accessible language and would confirm that sign languages are bona fide languages that meet the cognitive needs of the child. These lectures would also make students aware of important milestones in language development. Class meetings need to allow opportunities for open, unguarded discussion about sign language in general, deaf culture, deaf education, and realistic understanding of the benefits and limitations of amplification technology in language acquisition. 
In undergraduate medical clinical training, students need exposure to DHH patients who have made a variety of language and cultural self-identification decisions [103], and they need to learn how to work with sign language interpreters [104]. This can be achieved through appropriate case presentations, problem-based learning (PBL) sessions with DHH patients via an interpreter, DHH-simulated patients where both the patient and the interpreter give feedback, and lectures that include open, unguarded questions and answers with interpreters.

\section{Graduate Medical Education}

At least four residencies need to include additional information particular to the DHH child: family medicine, internal medicine, pediatrics, and otolaryngology. All these specialties call for a broad knowledge about amplification/CI, language in different modalities, and deaf education issues, and they call for establishing connections with local authorities and services that deal with these matters. Small group seminars should have visits from local practitioners, allowing frank discussion and exchange of practical information, including how to build liaisons with local authorities and services. Programs may benefit significantly from introducing these educational concepts to resident interns who are early in their training, so that they may incorporate these ideals into their emerging practice. Additionally, specialists in otolaryngology need to be able to discuss outcome variability and potential negative consequences frankly with patients and families, and would benefit from meeting a variety of successful deaf individuals who have made a spectrum of choices. They must understand the role of the family in the DHH child's health decisions and urge them to consult the relevant option grid [105]. They must understand the bio-ethical issues involved in CIs [55] and know how to foster patient/family fully informed consent [106].

\section{Continuing Medical Education}

Finally, the practicing physician needs continuing education about matters that affect DHH children and needs to stay up to date on those matters. Physicians in a variety of practice areas, including internal medicine, family medicine, emergency medicine, and psychiatry, if they have not had prior training, need to know how to work effectively with interpreters. Lectures by practitioners or researchers with deaf-related experience, case presentations by such specialists, and lectures by interpreters with extensive medical experience can foster this knowledge. Noon lectures, "lunch and learn" lectures, and Grand Round presentations are excellent ways to incorporate this learning, and they make this information accessible to emerging and established practitioners alike.

\section{Section Summary}

With the medical training recommended above, when a parent of a DHH newborn or early deafened small child comes for medical guidance, medical professionals will then ideally be able to give advice that protects the DHH child's ability to develop a first language, including information on first language acquisition and choices on language and education, as well as which medical specialists are indicated. Further, all medical professionals will know how to work with DHH children as they move from infancy into early language users into fully competent language users. From their preclinical classes, they will be aware of red flags that mark delays or gaps in language development, so they will be able to alert the family and help them take appropriate measures to protect the DHH child's cognitive health.

Table 1 summarizes these curricular recommendations, and adds a column on four present medical programs that can be looked to as a resource in each instance. We discuss these and other resources in the next section. The "Appendix" offers suggested readings and video clips that could be used in implementing these recommendations, organized by topic covered.

Innovative Programs that can Serve as Resources

While some medical institutions include deaf matters in their curriculum, none focus on the biological issues involved in first language acquisition with respect to the DHH child in their undergraduate curriculum. We stress that this focus is critical for the overall cognitive health of DHH children, so we strongly recommend that all medical institutions incorporate this topic into their undergraduate curriculum.

Beyond that particular recommendation, however, we list a variety of ways that medical institutions have incorporated deaf matters into their curriculum in order to show a range of changes that are possible. We offer these as examples of what has been done.

The University of Rochester Medical Center has been innovative with respect to meeting the health needs of DHH people across their life spans [107-112]. All first year undergraduate students participate in Deaf Strong Hospital, a rolereversal exercise in which students become "patients" who seek medical care from "doctors" who are really members of the Rochester Deaf Community. Students also have the choice of following the Deaf Health Pathway and prepare to care for deaf patients, take immersion sign language courses, have lectures on deaf culture and working with an interpreter, and do deaf outreach. Deaf patients take part in their simulated patient program. From 1998 to 2005, the URMC also gave lectures on the biopsychosocial model (BPMS) of treating psychiatric problems, many of which concerned deaf issues. 


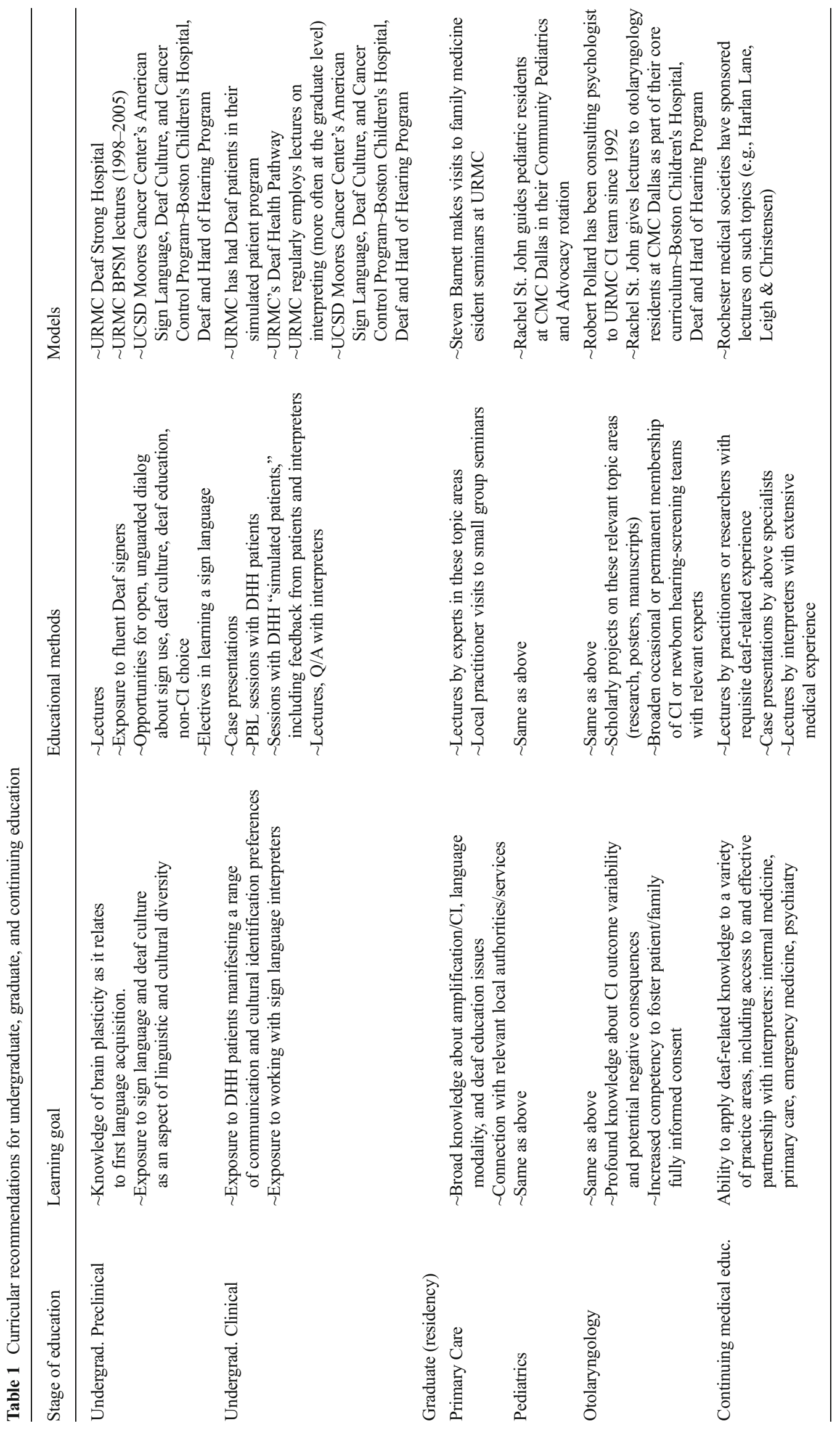


The Rebecca and John Moores Cancer Center at UCSD [113-118] trains undergraduate medical students to become cancer-control experts for both DHH and hearing patients in the American Sign Language, Deaf Culture and Cancer Control program. This 2-year program has the students interact with DHH patients, offers courses on deaf health care matters or deaf culture, offers classes in American Sign Language, and has an extensive set of outreach videos in ASL on a range of cancers.

Boston Children's Hospital has a Deaf and Hard of Hearing Program [119] that informs families about ASL, psychological issues that can arise with deaf children, and choices in the education of deaf children. They assess both spoken and sign language development, and they serve as a resource center, connecting families to relevant agencies.

Other efforts, while less comprehensive, are helpful examples. In Northern Ireland, Queen's University Belfast School of Medicine, Dentistry and Biomedical Sciences offers courses on deaf health care matters and deaf culture, does deaf outreach, and offers classes in British Sign Language [120-122]. Several medical schools or medical programs within educational institutions do at most one of these activities [123-128]. The Faculty of Medicine at Dalhousie University in Nova Scotia, Canada, held broad multidisciplinary elective workshops for first and second year medical students in 1997-1998 about deaf issues, which proved to be a lowcost and easily reproducible method of getting across essential information [129]. Even 1-day training courses on deaf awareness and communication skills have been shown to have positive results on the abilities of medical students to interact with DHH patients [130].

Among graduate programs, one that focuses on deaf children's needs and advising parents about the best language opportunities for their deaf infants/children is the FamilyFocused Center for Deaf and Hard of Hearing Children at the Children's Medical Center (CMC) of Dallas, TX [131]. Rachel St. John, the physician director, gained her training by putting together additional educational experiences, such as preparing for and gaining a certificate in interpreting, and graduate work in counseling at Gallaudet University. While neither her medical school nor her pediatric residency offered formalized courses to prepare her, her medical school provided a primary care grant opportunity focused on care for DHH patients, and her residency training program supported her in her initiative to develop a deaf-accessible pediatric clinic. [132]. She now serves as educational faculty for the pediatric residents at the CMC Dallas on their Community Pediatrics and Advocacy rotation, and for otolaryngology residents as part of their core curriculum lecture series. An experienced professional of this type can bring education and resources to bear to inform and train medical professionals at all levels.

Boston Children's Hospital offers a residency in otolaryngology as part of its Deaf and Hard of Hearing Program [119].
Besides serving the needs of deaf children and their families, it conducts basic research in and clinical studies of hearing.

Some medical schools have professionals who are deaf, some of whom provide services to the deaf community [133] and educate personnel in the medical school. Many providers have employees trained to work with deaf patients [134-138]. Gallaudet University maintains a website of hospitals that have centers designed specifically to meet the needs of deaf patients [139]. Many medical schools work to meet the needs of their own deaf students [140].

The Benefits of Implementing our Recommendations

The physician who has had the training recommended here will be able to:

- Explain the importance of a DHH child receiving a sign language before the age of 5 years old, and the potential consequences if that scenario does not happen

- Advise the parents of DHH infants/children about the language and education opportunities they have, with practical suggestions for the next steps that can be taken

- Explain why having a $\mathrm{CI} /$ hearing aid and learning a sign language are not mutually exclusive choices

- Provide arguments on the inadvisability of waiting to see how well a child performs with a CI or hearing aid before learning a sign language

The desired outcome will be that more DHH children will have healthy early language development in a sign language and, thus, fewer will be at risk for linguistic deprivation.

Acknowledgments The authors wish to thank the following people for discussions of what medical schools should cover with respect to deaf children and language, and where that information might fit within the curriculum: Julia Cooper, Wendy Eastman, Kim Kahng, George Lister, Mark Mai, and Chris Moreland. They thank the following people for information on what medical educational institutions in their country have done with respect to the needs of deaf people: Teri Hedding (USA), Lorraine Leeson (Ireland), Patrick Matthews (Ireland), Melanie Nakaji (USA), Jamina Napier (Australia and Scotland), Debra Russell (Canada), Rachel Sutton-Spence (UK), Laurie Swabey (USA), and Graham Turner (Scotland). They thank Zhenglong Zhou and Rachel St. John for editorial help on an earlier draft.

Funding/Support None.

Conflict of Interest None.

Ethical Approval Not applicable.

Previous Presentations None. 


\section{Appendix}

Case-based materials in which CI children are interviewed

Readings

Wheeler A, Archbold S, Gregory S, Skipp A. Cochlear implants: the young people's perspective. J Deaf Stud Deaf Edu. 2007; 12(3): 303-316.

Preisler G, Tvingstedt A-L, Ahlstrom M. Interviews with deaf children about their experiences using cochlear implants. Am Ann Deaf. 2005; 150(3): 260-267.

Videos

http://www.youtube.com/watch?feature=player_detailpage \&v= icPsm9RnO2E A deaf British girl explains what she "hears" and what she goes through to interpret the information the CI gives her and to maintain her speech skills so that hearing strangers can understand her. The video is all the more effective in demonstrating the need for a sign language, since this girl is among the "stars" with respect to CI success, yet it is her signing skills that afford her the possibility of communicating stress-free.

Case-based materials about CI children, but without the children's views

Readings

Andrews JF, Dionne V. Down the language rabbit hole with Alice: a case study of a deaf girl with a cochlear implant. Int J Otolaryng. 2011; Article ID 326379, 8 pages.

Hyde M, Punch R. The modes of communication used by children with cochlear implants and role of sign in their lives. Am Ann Deaf. 2011; 155(5): 535-549. (This is based on a survey of parents' and teachers' assessments.)

Swanwick R, Tsverik I. The role of sign language for deaf children with cochlear implants: Good practice in sign bilingual settings. Deafness Educ. Int. 2007; 9(4): 214-231. (This is about the role of signing in education in the UK.)

Videos

http://www.deafhh.net/wp/2011/02/08/through-your-child $\% E 2 \% 80 \%$ 99s-eyes-american-sign-language/ This shows children signing with parents, teachers, and each other. A deaf parent of a deaf child and an adult deaf woman give their views, along with the views of hearing parents and teachers.

http://www.theguardian.com/education/2014/jan/06/learning-to-sign-formy-child This website discusses parents who learned to sign to help their child develop language.

http://handeyes.wordpress.com/tag/rachel-benedict/ A deaf woman explains to parents of a deaf newborn that their worries are natural, and what they can do now so their baby will develop well.

First language acquisition and brain plasticity

Readings

Mayberry R, Eichen E. 38 in references.

Morford J, Hänel-Faulhaber B. 46 in references.

Cochlear implant issues

Readings

Peterson N, Pisoni D, Miyamoto R. 60 in references.

Humphries T, Kushalnagar P, Mathur G, Napoli DJ, Padden C, Rathmann $\mathrm{C}$, Smith S. Language 55 in references.

Bimodal bilingualism

Readings
Case-based materials in which CI children are interviewed

http://www.gallaudet.edu/daily_digest/vl2 products bilingualism.html This site has many readings, and the bibliographies in those readings are comprehensive.

Value of sign language for deaf children

Videos

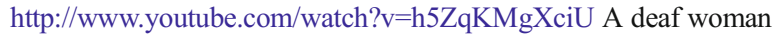
explains how the medical profession should approach hearing parents as they discuss a deaf child's hearing status and the journey ahead.

http://www.isaiah55.org/About-Us.html In Spanish, with English subtitles. It shows a linguistic deaf people who were gathered together and taught Mexican sign language. The people are excited, particularly the adolescents, at being able to communicate with each other effectively and without stress.

http://barnhorsel.se/ In Swedish. Google can translate it into English. Even without translation, it is obvious that these CI children are benefitting from sign language ability.

Open Access This article is distributed under the terms of the Creative Commons Attribution License which permits any use, distribution, and reproduction in any medium, provided the original author(s) and the source are credited.

\section{References}

1. Frost SB, Barbay S, Friel KM, Plautz EJ, Nudo RJ. Reorganization of remote cortical regions after ischemic brain injury: a potential substrate for stroke recovery. J Neurophysiol. 2003;89:3205-14.

2. Dancause N, Nudo RJ. Shaping plasticity to enhance recovery after injury. Prog Brain Res. 2011;192:273-95.

3. Sabel BA. Unrecognized potential of surviving neurons: withinsystems plasticity, recovery of function, and the hypothesis of minimal residual structure. Neuroscientist. 1997;3:366-70.

4. Prilloff S, Noblejas MI, Chedhomme V, Sabel BA. Two faces of calcium activation after optic nerve trauma: life or death of retinal ganglion cells in vivo depends on calcium dynamics. Eur $\mathbf{J}$ Neurosci. 2007;25(11):3339-46.

5. Sabel BA, Henrich-Noack P, Fedorov A, Gall C. Vision restoration after brain and retina damage: the "residual vision activation theory”. Prof Brain Res. 2011;192:199-262.

6. Kaas JH. Sensory loss and cortical reorganization in mature primates. Prog Brain Res. 2002;138:167-76.

7. Pascual-Leone A, Amedi A, Fregni F, Merabet LB. The plastic brain cortex. Annu Rev Neurosci. 2005;28:377-401.

8. Kupers R, Ptito M. Insights from darkness: what the study of blindness has taught us about brain structure and function. Prog Brain Res. 2011;192:17-31.

9. Knudsen EI. Sensitive periods in the development of the brain and behavior. J Cogn Neurosci. 2004;16:1412-25.

10. Hubel D, Wiesel T. Brain and visual perception: the story of a 25year collaboration. New York: Oxford University Press; 2005.

11. Cosetti M, Roland TJ. Cochlear implantation in the very young: issues unique to the under-1 population. Trends Amplif. 2010;14(1):46-57.

12. Hickok G, Poeppel D. The cortical organization of speech processing. Nat Rev Neurosci. 2007;8(5):393-402.

13. Gordon KA, Jiwani S, Papsin BC. What is the optimal timing for bilateral cochlear implantation in children? Cochlear Implants Int. 2011;12(2):S8-S14. 
14. Habib MG, Waltzman SB, Tajudeen B, Svirsky MA. Speech production intelligibility of early implanted pediatric cochlear implant users. Int J Pediatr Otorhinolaryngol. 2010;74(8):855-9.

15. Paludetti G, Conti G, Di Nardo W, De Croso E, Rolesi R, Picciotti $\mathrm{PM}$, et al. Infant hearing loss: from diagnosis to therapy official report of XXI conference of Italian society of pediatric otorhinolaryngology. Acta Otorhinolaryngol Ital. 2012;32(6):347-70.

16. Kral A, O'Donoghue GM. Profound deafness in childhood. NEJM. 2010;363:1438-50.

17. Argintaru N, Hamidi M, Allen L. Falling on deaf ears: overview of cochlear implantation issues in Canada and locally. UWOMJ I. 2011;80(2,1):12-3.

18. Pérez-Pereira M, Castro J. Language acquisition and the compensation of visual deficit: new comparative data on a controversial topic. Br J Dev Psychol. 1997;15(4):439-59.

19. Newport E, Meier R. The acquisition of American sign language. In: Slobin D, editor. The crosslinguistic study of language acquisition. Hillsdale: Lawrence Erlbaum Associates; 1985. p. 881-939.

20. Doidge N. The brain that changes itself: stories of personal triumph from the frontiers of brain science. New York: Viking; 2007.

21. Lenneberg E. Biological foundations of language. New York: Wiley; 1967.

22. Hudson C, Newport E. Getting it right by getting it wrong: when learners change languages. Cogn Psychol. 2009;59(1):30-66.

23. Woods BT, Carey S. Language deficits after apparent clinical recovery from childhood aphasia. Ann Neurol. 1979;6(5):405-9.

24. Martins IP. Persistent acquired childhood aphasia. In: Fabro F, editor. Neurogenic language disorders in children. Amsterdam: Elsevier; 2004. p. 231-51.

25. Goorhuis-Brouwer S. Enkele opmerkingen over afasie bij kinderen. Logopedie en Foniatrie. 1976;48:69-77.

26. Snow C, Hoefnagel-Höihle M. The critical period for language acquisition: evidence from second language learning. Child Dev. 1978;49(4):1114-28. Quote is from p. 1126.

27. Alajouanine T, Lhermitte F. Acquired aphasia in children. Brain. 1965;88(4):653-62.

28. Shattuck R. The forbidden experiment: the story of the wild boy of Aveyron. New york: Farrar, Straus and Giroux; 1980.

29. Curtiss S. Genie: a psycholinguistic study of a modern-day "wild child.". New York: Academic; 1977.

30. Cohn J. The two year window: The new science of babies and brains - and how it could revolutionize the fight against poverty. The New Republic. 9 November 2011. http://www.tnr.com/article/ economy/magazine/97268/the-two-year-window?passthru= Y z B $1 \mathrm{~N} \mathrm{D} \mathrm{J} \mathrm{m} \mathrm{M} \mathrm{m} \mathrm{R} \mathrm{k} \mathrm{Z} \mathrm{T} 1$ i N D g w Z D Y 4 M DhhYmIwMjYyYzh1Mjg\&utm_source=The+New + Republic\&utm_campaign=aff101360e-TNR_Daily_111411\&utm medium=email. Accessed 12 Sept 2012.

31. Zeanah $\mathrm{CH}$, Nelson CA, Fox NA, Smyke AT, Marshall P, Parker SW, et al. Designing research to study the effects of institutionalization on brain and behavioral development: the Bucharest early intervention project. Dev Psychopathol. 2003;15:885-907.

32. Nelson C, Fox M, Zeanah C, Johnson D. Caring for orphaned, abandoned and maltreated children: Bucharest Early Intervention Project. Powerpoint presentation at the 10 January 2007 Better Care Network Discussion Day in Washington, DC. http://www.unicef. bg/public/images/tinybrowser/upload/PPT\%20BEIP\%20Group \% 20for\%20website.pdf. Accessed 12 Sept 2012.

33. Drury SS, Theall KP, Gleason MM, Smyke AT, Devivo I, Wong JYY, et al. Telomere length and early severe social deprivation: linking early adversity and cellular aging. Mol Psychiatry. 2011;17(7):719-27.

34. Curtiss S. Language as a cognitive system: its independence and selective vulnerability. In: Otero C, editor. Noam Chomsky: critical assessments 4. London: Routledge; 1994. p. 211-55.
35. Grimshaw G, Adelstein A, Bryden M, MacKinnon G. Firstlanguage acquisition in adolescence: evidence for a critical period for verbal language development. Brain Lang. 1998;63(2):237-55.

36. Emmorey K, Corina D. Lexical recognition in sign language: effects of phonetic structure and morphology. Percept Mot Skills. 1990;71: 1227-52.

37. Emmorey K. Repetition priming with aspect and agreement morphology in American Sign Language. J Psycholinguist Res. 1991;20:365-88.

38. Mayberry R, Eichen E. The long-lasting advantage of learning sign language in childhood: another look at the critical period for language acquisition. J Mem Lang. 1991;30(4):486-512.

39. Mayberry R, Fischer S. Looking through phonological shape to lexical meaning: the bottleneck of non-native sign language processing. Mem Cogn. 1989;17:740-54.

40. Newport E. Maturational constraints on language learning. Cogn Sci. 1990;14(1):11-28.

41. Newport E, Supalla T. A critical period effect in the acquisition of a primary language. Unpublished ms. University of Rochester; 1987.

42. Galvan D. Differences in the use of American Sign Language morphology by deaf children: implications for parents and teachers. Am Ann Deaf. 1999;144(4):320-4.

43. Boyes BP. Rhythmic temporal patterns in the signing of deaf early and late learners of Swiss German Sign Language. Lang Speech. 1999;42:177-208.

44. Helmuth L. From the mouths (and hands) of babes. Science. 2001;293:1758-9.

45. Singleton J, Newport E. When learners surpass their models: the acquisition of American Sign Language from inconsistent input. Cogn Psychol. 2004;49:370-407.

46. Morford J, Hänel-Faulhaber B. Homesigners as late learners: connecting the dots from delayed acquisition in childhood to sign language processing in adulthood. Lang Ling Compass. 2011;5(8): 535-7.

47. Cormier K, Schembri A, Vinson D, Orfanidou E. First language acquisition differs from second language acquisition in prelingually deaf signers: evidence for sensitivity to grammaticality judgment in British Sign Language. Cognition. 2012;124(1):50-65.

48. Johnson JS, Newport E. Critical period effects in second language learning: the influence of maturational state on the acquisition of English as a second language. Cogn Psychol. 1989;21:60-99.

49. Newport E, Bavelier D, Neville HJ. Critical thinking about critical periods: perspectives on a critical period for language acquisition. In: Dupoux E, editor. Language, brain, and cognitive development: essays in honor of Jacques Mehler. Cambridge: MIT Press; 2001. p. 481-502.

50. Wood SK. Acquisition of topicalization in very late learners of Libras. In: Mathur G, Napoli DJ, editors. Deaf around the world: the impact of language. Oxford: Oxford University Press; 2010. p. 164-73.

51. Skotara N, Salden U, Kügow M, Hänel-Faulhaber B, Röder B. ERP comparison of deaf native signers and deaf signers with a delayed language acquisition. BMC Neurosci. 2012;13:44.

52. Mayberry R, Lock E. Age constraints on first versus second language acquisition: evidence for linguistic plasticity and epigenesist. Brain Lang. 2003;87(3):369-84.

53. Figueras B, Edwards L, Langdon D. Executive function and language in deaf children. J Deaf Stud Deaf Edu. 2008;13:362-77.

54. Kushalnagar P, Mathur G, Moreland CJ, Napoli DJ, Osterling W, Padden $\mathrm{C}$, et al. Infants and children with hearing loss need early language access. J Clin Ethic. 2010;21(2):143-54.

55. Humphries T, Kushalnagar P, Mathur G, Napoli DJ, Padden C, Rathmann C, Smith S. Language acquisition for deaf children: Reducing the harms of zero tolerance to the use of alternative approaches. Harm Reduct J. 2012; 9:16. http://www. harmreductionjournal.com/content/9/1/16. Accessed 1 Sept. 2012. 
56. Humphries T, Kushalnagar P, Mathur G, Napoli DJ, Padden C, Rathmann C, Smith S. Cochlear implants and the right to language: Ethical considerations, ideal situation, and practical measures toward reaching the ideal. In: Umat C, Tange RA, editors. Cochlear Implant Research Updates, InTech; 2012. http://inyurl.com/ 6qmexp9. Accessed 1 Sept. 2013.

57. Humphries T, Kushalnagar P, Mathur G, Napoli DJ, Padden C, Rathmann C, et al. Bilingualism: a pearl to overcome certain perils of cochlear implants. J Med Speech Lang Pathol. 2014;21(2):107-25.

58. Bouchard M-E, Ouellet C, Cohen H. Speech development in prelingually deaf children with cochlear implants. Lang Ling Compass. 2008;2:1-18.

59. Fink NE, Wang N-Y, Visaya J, Niparko JK, Quittner AL, Eisenberg LS. CDACI investigative team: childhood development after cochlear implantation $(\mathrm{CDaCl})$ study: design and baseline characteristics. Cochlear Implants Int. 2007;8(2):92-116.

60. Peterson N, Pisoni D, Miyamoto R. Cochlear implants and spoken language processing abilities: review and assessment of the literature. Restor Neurol Neurosci. 2010;28(2):237-50.

61. Szagun G. The younger the better? variability in language development of young German-speaking children with cochlear implants. In: Marinis T, Papangeli A, Stojanovik V, editors. Proceedings of the child language seminar 2007-30th anniversary. Reading, UK: University of Reading Press; 2008. p. 183-94.

62. Gulya A, Minor L, Poe D. Glasscock-Shambaugh's surgery of the ear. 6th ed. Shelton, CT: People's Medical Publishing House USA; 2010.

63. Santarelli R, De Filippi R, Genovese E, Arslan E. Cochlear implantation outcome in prelingually deafened young adults. Audiol Neurootol. 2008;13(4):257-65.

64. Nicholas JG, Tobey EA, Geers AE, Brenner C, Altuna D, Gabbert G. Factors associated with development of speech production skills in children implanted by the age of five. Ear Hear. 2003;24:36S46S.

65. Thoutenhoofd ED, Archbold S, Gregory S, Lutman ME, Nikolopoulos T, Sach TH. Paediatric cochlear implantation: evaluating outcomes. London: Whurr; 2005.

66. Nicholas JG, Geers AE. The process and early outcomes of cochlear implantation by three years of age. In: Spencer PE, Marschark M, editors. Advances in the spoken language development of deaf and hard-of-hearing children. Oxford: Oxford University Press; 2006. p. 271-97.

67. Yoshinaga-Itano C. Early identification, communication modality, and the development of speech and spoken language skills: patterns and considerations. In: Spencer PE, Marschark M, editors. Advances in the spoken language development of deaf and hardof-hearing children. Oxford: Oxford University Press; 2006. p. 298 327

68. O'Reilly RC, Mangiardi AJ, Bunnell T. Cochlear implants. In: DeLuca D, Leigh IW, Lindgren KA, editors. Access: multiple avenues for deaf people. WashingtonC: Gallaudet University Press; 2008. p. 38-74.

69. Martin D, Bat-Chava Y, Lalwani A, Waltzman SB. Peer relationships of deaf children with cochlear implants: predictors of peer entry and peer interaction success. J Deaf Stud Deaf Edu. 2010;16(1):108-20.

70. Grieco-Calub TM, Saffran JR, Litovsky RY. Spoken word recognition in toddlers who use cochlear implants. J Speech Lang Hear Res. 2009;52:1390-400.

71. Pisoni DB, Cleary M. Learning, memory, and cognitive processes in deaf children following cochlear implantation. In: Zeng F-G, Popper AN, Fay RR, editors. Cochlear implants: auditory prostheses and electrical hearing. New York: Springer; 2004. p. 377-426.

72. Burkholder RA, Pisoni DB. Working memory capacity, verbal rehearsal speed, and scanning in deaf children with cochlear implants. In: Spencer PE, Marschark M, editors. Advances in the spoken language development of deaf and hard-of-hearing children. Oxford: Oxford University Press; 2006. p. 328-57.

73. Marschark M, Rhoten C, Fabich M. Effects of cochlear implants on children's reading and academic achievement. J Deaf Stud Deaf Edu. 2007;12(3):269-82.

74. Kronenberger WG, Beer J, Castellanos I, Pisoni DB, Miyamoto RT. Neurocognitive risk in children with cochlear implants. JAMA Otolaryngol Head Neck Surg. 2014;140(7):608-15.

75. Giraud A-L, Lee H-J. Predicting cochlear implant outcome from brain organization in the deaf. Restor Neurol Neurosci. 2007;25: 381-90.

76. Watson L, Gregory S. Non-use of implants in children: child and parent perspectives. Deafness Educ Int. 2005;7(1):43-58.

77. Hogan N, Krebs HI. Physically interactive robotic technology for neuromotor rehabilitation. Prog Brain Res. 2011;192:59-68. Quote is from page 65 .

78. Jones LA. Tactile communication systems: optimizing the display of information. Prog Brain Res. 2011;192:113-28. Quote is from page 125.

79. Shannon R, Fu Q-J, Galvin J, Friesen L. Speech perception with cochlear implants. In: Zeng F-G, Popper AA, Fay RR, editors. Cochlear implants: auditory prostheses and electrical hearing. New York: Springer; 2010. p. 334-76. Quote is from p. 369.

80. Cohen NL, Roland JT. Complications of cochlear implant surgery. In: Waltzman SB, Roland JT, editors. Cochlear implants. 2nd ed. New York, NY: Thieme Medical Publishers; 2006. p. 126-32.

81. Rubin LG, Papsin B. Cochlear implants in children: surgical site infections and prevention and treatment of acute otitis media and meningitis. Pediatrics. 2010;126(2):381-91.

82. McJunkin J, Jeyakumar A. Complications in pediatric cochlear implants. Am J Otolaryng. 2010;31(2):110-3.

83. Thom JJ, Carlson ML, Olson MD, Neff BA, Beatty CW, Facer GW, et al. The prevalence and clinical course of facial nerve paresis following cochlear implant surgery. Laryngoscope. 2013;123(4):1000-4.

84. Steenerson RL, Cronin GW, Gary LB. Vertigo after cochlear implantation. Otol Neurotol. 2001;22:842-3.

85. Walker G. A conversation with grace walker: personal experiences with a cochlear implant. In: DeLuca D, Leigh IW, Lindgren KA, Napoli DJ, editors. Access: multiple avenues for deaf people. Washington, DC: Gallaudet University Press; 2008. p. 140-8.

86. Borkowski G, Hildmann H, Stark T. Surgical aspects of cochlear implantation in young and very young children. In: Kubo T, Takahashi Y, Iwaki T, editors. Cochlear implants: an update. The Hague: Kugler Publications; 2002. p. 223-6.

87. Marlowe AL, Chinnici JE, Rivas A, Niparko JK, Francis HW. Revision cochlear implant surgery in children: the Johns Hopkins experience. Otol Neurotol. 2010;31(1):74-82.

88. Snow JB, Wackym PA. Ballenger's otorhinolaryngology. 17th ed. Shelton: People's Medical Publishing House; 2008.

89. Tyler RS, Witt SA, Dunn CC, Perreau A, Parkinson AJ, Wilson BS. An attempt to improve bilateral cochlear implants by increasing the distance between electrodes and providing complementary information to the two ears. J Am Acad Audiol. 2010;21(1):52-65.

90. Tobin H. Rehabilitation research and development service: practical hearing aid selection and fitting. Baltimore: Department of Veterans Affairs; 1995.

91. Petitto LA, Zatorre RJ, Gauna K, Nikelski EJ, Dostie D, Evans AC. Speech-like cerebral activity in profoundly deaf people processing signed languages: implications for the neural basis of human language. Proc Natl Acad Sci. 2000;97(25):13961-6.

92. Hassanzadeh S. Outcomes of cochlear implantation in deaf children of deaf children: comparative study. J Laryngol Otol. 2012;126(1): 989-94.

93. Park GY, Moon IJ, Kim EY, Chung EW, Cho YS, Chung WH, et al. Auditory and speech performance in deaf children with deaf parents after cochlear implant. Otol Neurotol. 2013;34(2):233-8. 
94. Fellinger J, Holzinger D, Pollard R. Mental health of deaf people. Lancet. 2012;379:1037-44.

95. Luckner JL, Muir S. Successful students who are deaf in general education settings. Am Ann Deaf. 2001;146(5):435-46.

96. Luckner JL, Stewart J. Self-assessments and other perceptions of successful adults who are deaf: an initial investigation. Am Ann Deaf. 2003;148(3):243-50.

97. Crandall SJ, George G, Marion GS, Davis S. Applying theory to the design of cultural competency training for medical students: a case study. Acad Med. 2003;78(6):588-94.

98. Purnell, Larry D. Transcultural health care: A culturally competent approach. Philadelphia: FA Davis. 2012.

99. Tervalon M, Murray-Garcia J. Cultural humility versus cultural competence: a critical distinction in defining physician training outcomes in multicultural education. J Health Care Poor U. 1998;9(2):117-25.

100. Emanuel EJ. Changing premed requirements and the medical curriculum. JAMA. 2006;296(9):1128-31.

101. Flores $\mathrm{G}$. The impact of medical interpreter services on the quality of health care: a systematic review. Med Care Res Rev. 2005;62(3): 255-99.

102. Karliner LS, Jacobs EA, Chen AH, Mutha S. Do professional interpreters improve clinical care for patients with limited English proficiency? A systematic review of the literature. Health Serv Res. 2007;42(2):727-54.

103. Leigh I. A lens on deaf identities. Oxford: Oxford University Press; 2009.

104. Phelan M, Parkman S. How to work with an interpreter. BMJ. 1995;311(7004):555-7.

105. Mathur G, Napoli DJ, Padden C, Humphries T, Kushalnagar P, Rathmann C, Smith S, Durand M-A, Elwyn G. editors. Language options for deaf infants and children. 2013. http://www.optiongrid. org/resources/languageoptions_grid.pdf. Accessed 1 Jan 2014.

106. King JS, Moulton BW. Rethinking informed consent: the case for shared medical decision-making. Am J Law Med. 2006;32(4):429 501.

107. National Center for Deaf Health Research. Deaf Strong Hospital. 2014. http://www.urmc.rochester.edu/ncdhr/information/training/ deaf-strong-hospital.cfm. Accessed 15 Aug 2014.

108. Thew D, Smith SR, Chang C, Starr M. The deaf strong hospital program: a model of diversity and inclusion training for first-year medical students. Acad Med. 2012;87(11): $1496-500$.

109. Mathews JL, Parkhill AL, Schlehofer DA, Starr MJ, Barnett S. Deaf strong hospital: a role-reversal exercise emphasizing cultural competency and awareness. Am J Pharm Educ. 2011;75(3):53.

110. Richards J, Harmer L, Pollard P, Pollard R. Deaf strong hospital: an exercise in cross-cultural communication for first year medical students. J Univ Rochester Med C. 1999;10:5-7.

111. Pollard RQ. A consumer interview seminar that enhances medical student attitudes toward persons with disabilities. Ann Behav Sci Med Educ. 1998;5(1):27-31.

112. University of Rochester Medical Center. Medical education: Elective pathways, Deaf Health Pathway. 2014. http://www.urmc. rochester.edu/education $/ \mathrm{md} / \mathrm{prospective-students/elective-}$ pathways/deaf-health-pathway.cfm. Accessed 15 Aug 2014.

113. http://cancer.ucsd.edu/research-training/fellowships/asl/Pages/ default.aspx

114. Posner E. Medical students develop sign language skills. Access Press, February 10th, 2006. http://www.accesspress.org/2006/02/ medical-students-develop-sign-language-skills/. Accessed 1 January 2013.

115. Farber JH, Nakaji MC, Sadler GR. Medical students, deaf patients and cancer. Med Educ. 2004;38(11):1201.

116. Mueller P. Signs of the times: Medical students learn to serve the deaf. This Week@UCSD, December 20,2004. http://ucsdnews. ucsd.edu/archive/thisweek/2004/dec/12_20_cancercenter.asp. Accessed 1 Jan 2014.

117. Hoang L, LaHousse SF, Nakaji MC, Sadler GR. Assessing deaf cultural competency of physicians and medical students. J Cancer Educ. 2011;26:175-82.

118. UC San Diego Moores Cancer Center. ASL cancer education program for the deaf and hard of hearing. n.d. http://cancer.ucsd.edu/ coping/resources-education/deaf-info/Pages/default.aspx. Accessed 15 Aug 2014.

119. Boston Children's Hospital. Deaf and Hard of Hearing Program. http://www.childrenshospital.org/centers-and-services/deaf-andhard-of-hearing-program/overview. Accessed 6 Oct 2014.

120. Queen's University Belfast. Centre for Medical Education. eLearning. n.d. http://www.qub.ac.uk/schools/mdbs/medicine/ AboutUs/eLearning. Accessed 15 Aug 2014.

121. Queen's University Belfast. School of Medicine, Dentistry and Biomedical Sciences. News: School awarded for breaking down communication barriers. Summer 2014. http://www.qub.ac.uk/ schools/mdbs/News/. Accessed 15 Aug 2014.

122. Action on hearing loss. Find a hear to help service in your area. n.d. http://www.actiononhearingloss.org.uk/supporting-you/hear-tohelp-hearing-aid-support/find-a-hear-to-help-service-in-your-area. aspx. Accessed 15 Aug 2014.

123. Gallaudet University. Counseling and psychological services. 2014. http://www.gallaudet.edu/counseling_and_psychological_services. html. Accessed 15 Aug 2014.

124. Howard University Hospital. Psychiatry and behavioral sciences. About us. n.d. http://healthsciences.howard.edu/healthcare/hospital/ departments/psychiatry-behavioral-sciences/about-us. Accessed 15 Aug 2014.

125. Archive: On The Green. Mental Health Center program helps medical students understand deaf patients' issues. August 2, 2000. 30 (21). http://pr.gallaudet.edu/otg/BackIssues.asp?ID=504. Accessed 1 Jan 2014

126. Boonshoft School of Medicine, Wright State University. Substance abuse resources \& disability issues. 2013. http://www.med.wright. edu/citar/sardi/doda. Accessed 15 Aug 2014.

127. Trinity College Dublin, Faculty of Health Sciences, School of Nursing \& Midwifery. Perspectives on deafness. 2011. http:// www.tcd.ie/Nursing_Midwifery/assets/undergraduate/pdf/ NU2E01-Perspectives-on-Deafness.pdf. Accessed 15 Aug 2014.

128. University of Stirling. School of Nursing, Midwifery and Health. Mental health nursing. n.d. http://www.nm.stir.ac.uk/applicants-ug/ mental-health-nursing.php. Accessed 15 Aug 2014.

129. Lock E. A workshop for medical students on deafness and hearing impairments. Acad Med. 2003;78(12):1229-34.

130. Smith MCA, Hasnip JH. The lessons of deafness: deafness awareness and communication skills training with medical students. Med Educ. 1991;25(4):319-21.

131. Family-Focused Center for Deaf and Hard of Hearing Children. Children's Medical Center Family-Focused Center (FFC) for Deaf and Hard of Hearing Children works with patients, their families and their physicians to provide resources and education regarding hearing needs. n.d. http://www.childrens.com/Assets/Documents/ healthcare-professionals/SchoolNurses/ffc-flier-english.pdf. Accessed 15 Aug 2014.

132. MedTerp: Where Medicine and Interpreting Connect. n.d. http:// medterp.weebly.com/who-we-are.html. Accessed 15 Aug 2014.

133. Dawson T. Deaf medical resident on path to becoming 'amazing physician' (with video). Edmonton Journal. February 14, 2014. http://www.edmontonjournal.com/Deaf + medical + resident+path + becoming+amazing+physician+with+video/9496393/story.html. Accessed 15 Aug 2014

134. National Health Service of Scotland. Other languages. Free pilot BSL video relay service (VRS). n.d. http://www.nhs24.com/ ContactUs/OtherLanguages/BSL. Accessed 15 Aug 2014. 
135. The Alabama Department of Mental Health. Deaf services. n.d. http://www.mh.alabama.gov/MIDS/. Accessed 15 Aug 2014.

136. Deaf Community Health Worker Project. Partnering with you in healthcare. (Minnesota). 2011. http://www.deafchw.org/. Accessed 15 Aug 2014.

137. Hennepin County Medical Center, MN. Programs \& services. Deaf \& immigrant center for education. 2014. http://hcmc.org/services/ HCMC MAINCONTENT 407. Accessed 15 Aug 2014.

138. Mount Sinai Hospital. Sinai deaf health. 2014. http://www.sinai.org/ patients-visitors/patients/sinaideafhealth. 15 Aug 2014.
139. Gallaudet University Laurent Clerc National Deaf Education Center. Healthcare for deaf and hard of hearing patients: clinics and special services. n.d. http://www.gallaudet.edu/clerc_center/ information_and_resources/info_to_go/educate_children_(3 to 21)/social-emotional_development/mental health and_wellness/ healthcare_delivery_for_dhoh_patients_clinicsspec_svcs.html. Accessed 15 Aug 2014.

140. NHS Lothian. Scottish mental health service for deaf people. 2012. http://www.nhslothian.scot.nhs.uk/Services/A-Z/mhdeafservice/ Pages/default.aspx. Accessed 15 Aug 2014. 